\title{
Article \\ Reusing Flowback and Produced Water with Different Salinity to Prepare Guar Fracturing Fluid
}

\author{
Erdong Yao ${ }^{1,2}$, Hang $\mathrm{Xu}^{1,2, *}$, Yuan $\mathrm{Li}^{1,2}{ }^{\text {, Xuesong Ren }}{ }^{1}$, Hao Bai ${ }^{1,2}$ and Fujian Zhou ${ }^{1,2, *}$ \\ 1 Unconventional Petroleum Research Institute, China University of Petroleum (Beijing), Beijing 102249, China; \\ yaoed@cup.edu.cn (E.Y.); 2017310210@student.cup.edu.cn (Y.L.); renxuesong17_rsc@163.com (X.R.); \\ 15927880862@163.com (H.B.) \\ 2 State Key Laboratory of Petroleum Resource and Prospecting, China University of Petroleum (Beijing), \\ Beijing 102249, China \\ * Correspondence: cup_xh@163.com (H.X.); zhoufj@cup.edu.cn (F.Z.)
}

check for updates

Citation: Yao, E.; Xu, H.; Li, Y.; Ren, X.; Bai, H.; Zhou, F. Reusing Flowback and Produced Water with Different Salinity to Prepare Guar Fracturing Fluid. Energies 2022, 15, 153. https://doi.org/10.3390/ en15010153

Academic Editor: Alireza Nouri

Received: 3 November 2021

Accepted: 23 December 2021

Published: 27 December 2021

Publisher's Note: MDPI stays neutral with regard to jurisdictional claims in published maps and institutional affiliations.

Copyright: (c) 2021 by the authors. Licensee MDPI, Basel, Switzerland. This article is an open access article distributed under the terms and conditions of the Creative Commons Attribution (CC BY) license (https:// creativecommons.org/licenses/by/ $4.0 /)$.

\begin{abstract}
Economical and environmental concerns have forced the oil and gas industry to consider reusing flowback and produced water for fracturing operations. The major challenge is that the highsalinity of flowback water usually prevents its compatibility with several fracturing fluid additives. In this paper, the authors explored an economic and effective method to prepare guar fracturing fluids with different salinity waters. The main research idea was to use chelating agents to mask metal ions, such as calcium and magnesium, that are harmful to crosslinking. Firstly, a complexometric titration test was conducted to measure the chelating ability of three chelating agents. Secondly, through viscosity, crosslinking, and hanging tests, it was verified that the complex masking method could cope with the problem of high-valence metal ions affecting crosslinking. Thirdly, the preferred chelating agent was mixed with several other additives, including thickeners, crosslinkers, and $\mathrm{pH}$ regulators, to prepare the novel guar fracturing fluid. The comprehensive performances of the novel fluid system were tested such as temperature and shear resistance, friction reduction, gel-breaking performance, and core damage rate. The results show that the organophosphate chelating agent (i.e., CA-5) had the greatest ability to chelate calcium and magnesium ions. There was a good linear relationship between the dosage of CA- 5 and the total molar concentration of calcium and magnesium ions in brine water. The main mechanism was that the chelating agent formed a complex with calcium and magnesium ions at a chelation ratio of 1:5. The test results of the comprehensive performance evaluation indicate that the prepared guar fracturing fluid met the requirements for field application, and the lower the salinity of the flowback water, the more it is economical and effective.
\end{abstract}

Keywords: flowback and produced water; chelating agent; complex masking method; crosslinker; chelation ratio

\section{Introduction}

Hydraulic stimulation is an effective method to enhance oil recovery from unconventional reservoirs such as tight oil/gas and shale oil/gas reservoirs [1-3]. However, with the continuous successful exploration and development of terrestrial and marine oil and gas resources, large volumes of water containing very high concentrations of total dissolved solids (TDS) return to the surface. Economical production of unconventional oil and gas resources requires the creative management of flowback and produced water to prevent the pollution of surface water resources and to protect the ecological environment. Currently, formulating a hydraulic fracture fluid with flowback water is an obvious solution for economically feasible and environmentally sustainability $[4,5]$.

However, there are some negative effects of reusing the flowback water. On the one hand, the TDS concentration in flowback water can reach five times that of sea water, and the contained cations will affect the hydration and swelling properties of conventional polymer thickeners, resulting in inadequate dissolution or even insolubility [6-8]. On 
the other hand, the crosslinking reaction relies on the network structure formed by the dehydration condensation of borate ions and hydroxyl groups. But the presence of $\mathrm{Ca}^{2+}$ and $\mathrm{Mg}^{2+}$ will react with the hydroxyl groups in the solution to form precipitates, which reduces the amount of hydroxy boron generated and seriously affects the crosslinking effect. In addition, there is a large amount of organic matter and saprophytic bacteria in flowback and produced water, making the thickeners susceptible to microbial corrosion and deterioration during the formulation process. Hence, it is necessary to carry out research on how to effectively formulate fracturing fluid using high-salinity water.

One of the primary challenges in formulating fracturing fluids with high-salinity water is the dissolution of thickeners. At present, guar-based fluids are commonly used as hydraulic fracturing fluids. When using high-salinity water to prepare the guar gum solution, for ionic guar gum, the strong electrolytes in water can quickly penetrate the polymer particles before water molecules to shield the effective charge, thus weakening the chain expansion caused by inter-ion repulsion, resulting in smaller sizes and poorer swelling properties [9-11]. Banerjee et al. [12] found that metal cations can affect the molecular chain conformation of carboxymethyl hydroxypropyl guar gum (CMHPG) through electrostatic interactions: the chain volume is compressed, the hydrodynamic volume becomes smaller, and the intrinsic viscosity is reduced. For non-ionic guar gum, Gittings et al. [13] found that salt ions have a great influence on the conformation of the guar gum molecular chain, resulting in a decrease in the storage modulus and loss modulus of the solution. Another challenge in formulating fracturing fluids with high-salinity flowback water is the crosslinking problem. The boron crosslinking agents always worked in an alkaline environment. As the reservoir temperature rises, $\mathrm{Ca}^{2+}$ and $\mathrm{Mg}^{2+}$ start to consume the hydroxyl ions and produce hydroxide precipitates, lowering the $\mathrm{pH}$ of the system, which has disadvantages for the crosslinking reaction. The generated precipitation can also cause certain damage to the formation [14].

Different approaches have been applied in the literature to settle the difficulties of reusing flowback water to prepare fracturing fluid. Ali et al. [15] put forward the idea of adjusting the $\mathrm{pH}$ value of the crosslinking reaction system between borate ion and hydroxypropyl guar gum in a lower range to avoid the formation of hydroxide precipitation. Fedorov et al. [16] introduced a case study of hydraulic fracturing using produced water in western Siberia. This study used chelating agents and changes in the $\mathrm{pH}$ value of the flowback water to successfully formulate fracturing fluids with reliable rheology. LeBas et al. [17] introduced the application of electrocoagulation (EC) methods for the treatment of flowback water with the TDS as high as $267,588 \mathrm{mg} / \mathrm{L}$. In EC, heavy metals ions and colloids are held in solution mainly by charge and particle size. Treated flowback water together with CMHPG and zirconium crosslinker were used to prepare fracturing fluids, which was used to successfully fracture seven wells with 97 fracturing stages. Gupta et al. [18] proposed to formulate an amphoteric polymer fracturing fluid system with high-salinity produced water and achieved good results. Since the late 1990s, viscoelastic surfactant (VES) clean fracturing fluid has been widely used in fracturing stimulations of low-permeability reservoirs due to the fact of its good sand-carrying, fracture-forming performance and low damage characteristics. Bulat et al. [19] presented a new flowback water-based clean fracturing fluid system, NG-VES, consisting of an amphoteric surfactant and a rheology optimizer as the main formulation. When the polar ends of the amphoteric surfactants are equal in the anion and cation parts, the "internal salt" formed by the system is neutral. At this time, the electrostatic performance of the surfactant will not be affected by the electrolyte in the solvent. This salt resistance property guarantees the performance of the system in flowback water.

Chelating agents are compounds capable of forming water-soluble metal complexes with divalent and trivalent cations [20]. Because the chelating agents contain coordination atoms with greater negative charge, it can form cyclic compounds through strong coordination interaction with metal ions, thereby masking these metal ions. Chelating agents have various applications in the oil and gas industry such as iron control, scale removal, and 
as standalone stimulation fluid for acidizing [21]. Liu et al. [22] developed a hydroxy acid chelating agent, $\mathrm{AO}-1$, for fracturing, and used base fluids with $\mathrm{Ca}^{2+}$ and $\mathrm{Mg}^{2+}$ concentrations of $150.67 \mathrm{mg} / \mathrm{L}$ and $264.28 \mathrm{mg} / \mathrm{L}$ to prepare fracturing fluids. Elsarawy et al. [20] selected and evaluated five different chelating agents and finally concluded that $\mathrm{N}-(2-$ hydroxyethyl) ethylenediamine- $\mathrm{N}, \mathrm{N}^{\prime}, \mathrm{N}^{\prime}$-triacetic acid (HEDTA) and glutamic acid $\mathrm{N}$, $\mathrm{N}$-diacetic acid (GLDA) enabled the increase in the resistance of fracturing fluid systems to $\mathrm{Ca}^{2+}$ and $\mathrm{Mg}^{2+}$, having a better complexing and masking capacity. Muhammad et al. [8] introduced a new smart fracturing fluid system that consists of GLDA and which can replace biocide, clay stabilizer, crosslinker, and breaker from fracturing fluid formulation. Although many scholars have conducted large amounts of research on chelating agents, it is still necessary to explore economical and effective chelating agents suitable for masking metal ions that are harmful to crosslinking as well as to establish a chart for preparing fracturing fluids with different salinity flowback water.

In this work, a novel guar fracturing fluid was prepared by reusing flowback and produced water with different salinities. Organophosphate chelating agent, CA-5, was preferred to mask the harmful metal ions in high-salinity water, and a relationship chart on the dosage of CA- 5 added and the total molar concentration of calcium and magnesium ions in the solution was obtained. The chelating agent, CA-5, together with hydroxylpropyl guar gum JK101, self-synthesized organic boron crosslinker YZ-1, and $\mathrm{pH}$ regulator YC150, consisted of the novel guar fracturing fluid system. Viscosity, crosslinking, and hanging tests were performed to determine the optimal conditions and dosages of the various additives. At last, the novel fluid system was tested to evaluate its comprehensive performances including temperature and shear resistance, friction reduction, gel-breaking performance, and core damage rate. The results show that the novel guar fracturing fluid prepared by reusing flowback water with the highest salinity met the requirements of field operation. The lower the salinity of the flowback water, the more it is economical and effective.

\section{Materials and Methods}

\subsection{Materials and Devices}

The thickener, hydroxypropyl guar gum JK101, of industrial grade, was made by Petrochemical Kunshan Co., Ltd. (Kunshan, China) Organic carboxylic acid chelating agent CA-1, amino carboxylic acid chelating agent CA-3, and organophosphate chelating agent CA-5, of analytical purity, were purchased from Aladdin Biochemical Technology Co., Ltd. (Shanghai, China). Crosslinker YP-1 and regulator YC-150, industrial grade, self-made; borax, sodium gluconate, sodium hydroxide, glycerol, calcium chloride, sodium chloride, potassium chloride, magnesium chloride, sodium bicarbonate, and sodium carbonate, of analytical purity, were provided by Hongyan Chemical Reagent Factory (Hedong District, Tianjin, China). Hydrochloric acid, acetic acid, and ammonium persulfate, of analytical purity, were purchased from China State Pharmaceutical Group Chemical Reagent Co., Ltd. (Shanghai, China).

The HAAKE MARS III type rheometer was manufactured by Haake Technik GmbH. The XY-1 type electric thermostat was produced by Xuan Yuan Heating Equipment Technology Co., Ltd. (Yancheng city, Shandong Province, China). The Viscometer OFITE 900 was made by Bogong Experimental Equipment Factory (Shanghai, China). The YMC-2 type loop friction test system was produced by Hai'an Petroleum Instruments Co., Ltd. (Nantong, China).

\subsection{Preparation of Water Samples with Different Salinity}

The TDS of formation water and flowback water in different oil and gas blocks in western China is approximately 4000 300,000 $\mathrm{mg} / \mathrm{L}$. In this paper, five kinds of flowback and produced water samples from different blocks were used to prepare simulated brine in the lab for subsequent experiments. According to the field water analysis reports, the corresponding inorganic salts were selected and added to the distilled water to prepare the 
water samples. Table 1 shows the analysis reports of five produced water samples. The content of $\mathrm{Ca}^{2+}$ and $\mathrm{Mg}^{2+}$ in the field water was relatively high. To study the relationship between chelating agent dosage and the total molar concentration of $\mathrm{Ca}^{2+}$ and $\mathrm{Mg}^{2+}$, all five water samples were used in dosage optimization experiments. In addition, the highest salinity water sample, E, was chosen for fracturing fluid formulation optimization.

Table 1. Composition of flowback and produced water salinity.

\begin{tabular}{cccccc}
\hline Ion Type & $\begin{array}{c}\text { Sample A } \\
(\mathbf{m g} / \mathrm{L})\end{array}$ & $\begin{array}{c}\text { Sample B } \\
(\mathbf{m g} / \mathrm{L})\end{array}$ & $\begin{array}{c}\text { Sample C } \\
(\mathbf{m g} / \mathrm{L})\end{array}$ & $\begin{array}{c}\text { Sample D } \\
(\mathbf{m g} / \mathrm{L})\end{array}$ & $\begin{array}{c}\text { Sample E } \\
(\mathbf{m g} / \mathrm{L})\end{array}$ \\
\hline $\mathrm{K}^{+}+\mathrm{Na}^{+}$ & 1733.94 & 5386.3 & - & 9640.7 & $115,124.4$ \\
$\mathrm{Mg}^{2+}$ & 7.22 & 43.3 & 282 & 83.2 & 2309 \\
$\mathrm{Ca}^{2+}$ & 17.85 & 17.2 & 1462 & 396.9 & 458.5 \\
$\mathrm{Cl}^{-}$ & 2539.28 & 7355.2 & 21,742 & $15,028.4$ & $178,948.8$ \\
$\mathrm{HCO}_{3}^{-}$ & 112 & 1836.5 & 69 & 349.1 & 215.4 \\
$\mathrm{OH}^{-}$ & 2.13 & - & - & 4.7 & - \\
$\mathrm{CO}_{3}^{2-}$ & 246.26 & - & - & 34.2 & - \\
$\mathrm{SO}_{4}^{2-}$ & 58.00 & 49.4 & 1050 & 2676.2 & 8012.4 \\
$\mathrm{TDS}^{2-}$ & 4716.68 & $14,687.9$ & 24,605 & $26,313.7$ & $305,068.5$ \\
\hline
\end{tabular}

\subsection{Synthesis of Crosslinker}

Plenty of studies have shown that organic boron crosslinkers have superior properties in gel breaking and delayed crosslinking $[23,24]$. In this study, sodium gluconate and organic alcohol amine were used to synthesize organic boron crosslinker, which can enhance coordination and be beneficial to achieve crosslinking in high-salinity brine. The new organic boron crosslinker (i.e., YZ-1) was synthesized as follows: (1) mix water and glycerol at a ratio of $3: 1$, and then add $50 \mathrm{~g}$ of the mixed solution to a three-necked flask and gradually raise the temperature to $60{ }^{\circ} \mathrm{C}$; (2) add $4 \mathrm{~g}$ of sodium hydroxide and $15 \mathrm{~g}$ of borax to the three-necked flask and stir until the solid is completely dissolved; (3) drop $15 \mathrm{~g}$ mannitol into the three-necked flask with stirring; (4) add $8 \mathrm{~g}$ of sodium gluconate to the flask, raise the temperature to $60{ }^{\circ} \mathrm{C}$ and react for $3 \mathrm{~h}$. After the reaction, the clear and transparent organic boron crosslinker, YZ-1, was obtained.

\subsection{Complexometric Titration Experiment}

The presence of high valence cations, such as $\mathrm{Ca}^{2+}$ and $\mathrm{Mg}^{2+}$, in flowback water has a significant impact on the performance of fracturing fluids, which can be effectively addressed by adding chelating agents [20]. In this study, the chelating ability of three different chelating agents were quantitatively evaluated by complexation titration experiments. The main steps were as follows: (1) Prepare $30 \mathrm{~mL}$ of $1 \mathrm{wt} . \% \mathrm{Na}_{2} \mathrm{CO}_{3}$ solution and divide it equally into six test tubes, and then divide the test tubes into two groups (i.e., Group A and Group B) and add chelating agents CA-1, CA-3, and CA-5, respectively, to each group, forming a chelating agent dispersion system of $5 \mathrm{wt}$.\% concentration with stirring; (2) use a burette to add $1 \mathrm{~mol} / \mathrm{L} \mathrm{CaCl}_{2}$ solution dropwise to the test tubes of group $\mathrm{A}$, while adding $1 \mathrm{~mol} / \mathrm{L} \mathrm{MgCl}_{2}$ solution to group $\mathrm{B}$, and then record the consumption until white turbid precipitates start to appear in each test tube; (3) based on the volume of $\mathrm{CaCl}_{2} / \mathrm{MgCl}_{2}$ solution consumed, the chelation value can be calculated for each chelating agent using the following equation [22]:

$$
L=\frac{V_{2} c_{2} M r_{2}}{V_{1}}
$$

where $L$-chelation value, $\mathrm{mg} / \mathrm{mL} ; V_{2}$ consumption volume of the metal ion solution, $\mathrm{mL}$; $V_{1}$ chelating agent solution volume, $\mathrm{mL} ; M r_{2}$ molecular weight of metal ions, $\mathrm{mg} / \mathrm{mol} ; c_{2}$ molar concentration of metal ions, $\mathrm{mol} / \mathrm{mL}$. 


\subsection{Preparation of Fracturing Fluid}

The selected flowback water sample and chelating agent were weighed according to the formula, and then poured into the agitator. The rotation speed of the agitator was adjusted until the top of the shaft of the agitator blade could be seen in the vortex formed by the liquid. The thickener, JK101 guar gum, was avoided to avoid the formation of "fisheyes". The stirrer was turned off after the solution was stirred evenly, and it was left for a few minutes to obtain the base fluid. The crosslinked gel fracturing fluid was obtained by adding a corresponding mass of the regulator, YC-150, and the crosslinker, YP-1, to the base fluid.

\subsection{Fracturing Fluid Performance Test}

\subsubsection{Temperature and Shear Resistance Test}

The prepared novel guar fracturing fluid was loaded into a HAAKE MARS III rheometer, heated to $150{ }^{\circ} \mathrm{C}$ at a rate of $3.0 \pm 0.1{ }^{\circ} \mathrm{C} / \mathrm{min}$, and sheared for $80 \mathrm{~min}$ at $170 \mathrm{~s}^{-1}$. The apparent viscosity with temperature was recorded, and the temperature and shear resistance of the fracturing fluid were evaluated. The thermal stability depends on the final viscosity after shearing for $80 \mathrm{~min}$. When the final viscosity remained above $50 \mathrm{mPa} \cdot \mathrm{s}$, the fracturing fluid system was deemed to have excellent temperature resistance and shear resistance.

\subsubsection{Friction Reduction Test}

Friction reduction performance is mainly characterized by the friction reduction rate, which can be calculated by testing the friction pressure drop generated by the fluid flowing in the pipeline. The frictional pressure was tested by the difference generated when fresh water and fracturing fluid flowed through the same straight pipe, respectively, and the friction reduction rate can be calculated by the following Equation (2). The YMC-2 type loop friction test system was employed to measure the friction reduction rate as shown in Figure 1. It is mainly composed of a liquid supply system (a), screw pump (b), pipeline system (c), and integrated control computer (d). During the experiment, the initial displacement of the screw pump was $250 \mathrm{~kg} / \mathrm{h}$, and then it gradually increased with $250 \mathrm{~kg} / \mathrm{h}$ as a step increment until $2500 \mathrm{~kg} / \mathrm{h}$; thus, the corresponding relationship between the friction reduction rate and the displacement could be obtained. It is worth noting that the friction reduction rate test only uses the base fluid instead of the crosslinked gel fracturing fluid, which reflects the delayed crosslinking characteristics of the fracturing fluid during the actual wellbore flow.

$$
F R=\left(\Delta P_{w}-\Delta P_{f}\right) / \Delta P_{w} \times 100 \%
$$

where $F R$ is the friction reduction rate, $\% ; \Delta P_{w}$ is the frictional pressure difference generated by fresh water, $\mathrm{MPa} ; \Delta P_{f}$ is the frictional pressure difference generated by fracturing fluid, MPa. 


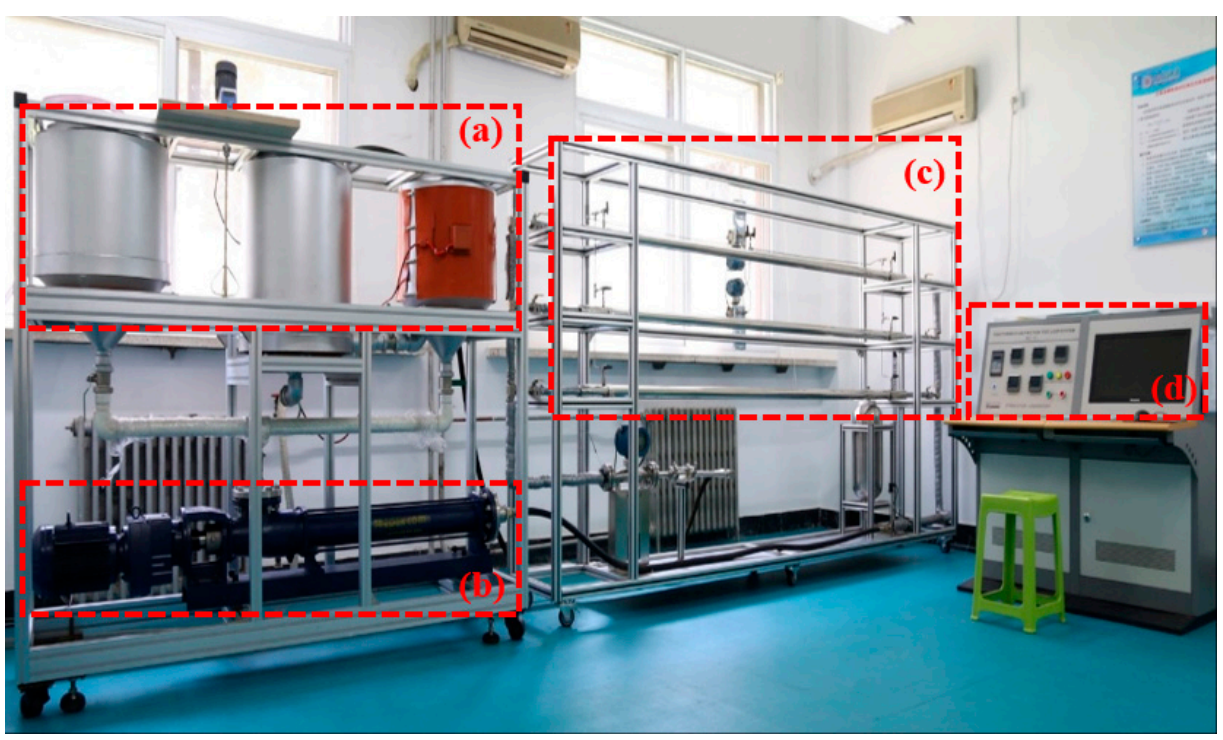

Figure 1. The YMC-2 type loop friction test system. (a) liquid supply system, (b) screw pump, (c) pipeline system, and (d) integrated control computer.

\subsubsection{Gel-Breaking Test}

The prepared fluid system was poured into a sealed container, and $0.05 \mathrm{wt} . \%$ ammonium persulfate was added as breaker. Then, the fracturing fluid was moved into an oil bath, which was preset as a reservoir temperature. An OFITE 900 Viscometer was used to measure the viscosity of the gel-breaking fluid at different times. When the viscosity as lower than $5 \mathrm{mPa} \cdot \mathrm{s}$, it was completely broken. Guar gum is difficult to completely degrade due to the fact of its molecular structure, and a large amount of flocculent residue will appear after the fluid is placed for a period. All the broken gel fluid was transferred into the dried and constant mass centrifugal tube and centrifuged at a speed of $3000 \pm 150 \mathrm{r} / \mathrm{min}$ for $30 \mathrm{~min}$. The supernatant was poured out after centrifugation, and then the tube was dried in an oven at $110 \pm 5^{\circ} \mathrm{C}$ to a constant weight, weighed, and the residue content was calculated according to Equation (3), where $\eta$ is the residue content, $\mathrm{mg} / \mathrm{L} ; m$ is the mass of residue, $\mathrm{mg} ; V$ is the volume of gel-breaking fluid, $\mathrm{mL}$.

$$
\eta=\frac{m}{V} \times 1000
$$

\subsubsection{Formation Damage Test}

In the process of hydraulic fracturing, many factors, such as the gel-breaker residue, water blockage, emulsification phenomenon, and reservoir sensitivity, will cause the reservoir matrix to become damaged, which is not conducive to the flow of crude oil from the matrix into the fractures [25-27]. Formation damage experiments were evaluated by a multi-functional core flow system as shown in Figure 2. The principle is to calculate the permeability of the core before and after the damage using the Darcy formula. The core displacement experimental steps are as follows: (1) first use $2 \mathrm{wt} . \% \mathrm{KCl}$ solution to completely displace the core, and then after the liquid is stably discharged from the outlet end of the core holder, the core permeability, $\mathrm{K}_{1}$, before the damage is calculated; (2) stop the pump and switch the valve to reversely drive a certain volume of gel-breaking liquid until the fluid is discharged from the outlet; (3) switch the valve again, and then drive the $2 \mathrm{wt}$. $\mathrm{KCl}$ solution forward to obtain the stable permeability, $\mathrm{K}_{2}$. According to Equation (4), the core damage rate $(\omega)$ can be calculated by:

$$
\omega=\frac{K_{1}-K_{2}}{K_{1}} \times 100 \%
$$




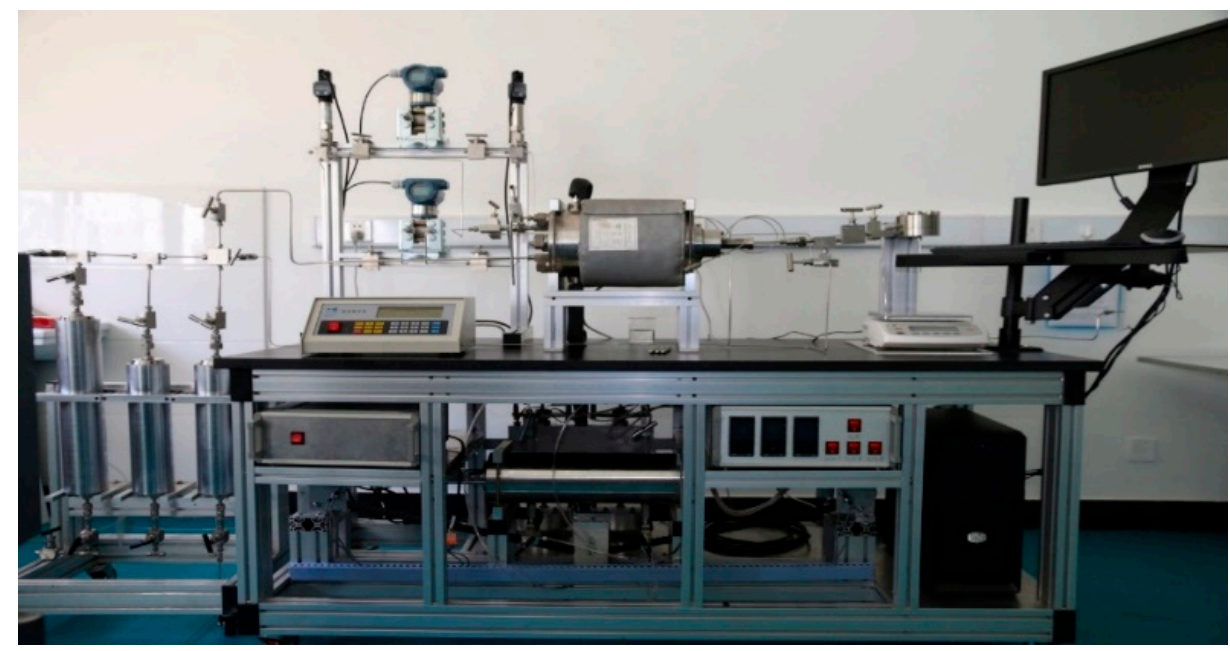

Figure 2. Multi-functional core flow system.

\section{Results and Discussion}

\subsection{Optimization of Fracturing Fluid Formula}

\subsubsection{Thickener}

JK101 guar gum is a white to light yellow powder with a non-ionic chemical structure. It has good dispersion and solubility in water, appearing to have an excellent shear dilution performance and electrolyte resistance. The JK101 guar gum base fluid with a mass fraction of $0.45 \mathrm{wt} . \%$ was dissolved in distilled water, fully stirred to swell and thicken, as shown in Figure 3. The apparent viscosity of the base liquid at different temperatures was measured with an OFITE 900 Viscometer as shown in Table 2. It can be seen from the data that the apparent viscosity at room temperature was $60.2 \mathrm{mPa} \cdot \mathrm{s}$, which meets the technical index of the water-based fracturing fluid thickener; thus, the optimal dosage of JK101 was 0.45 wt.\% in the subsequent experiments.

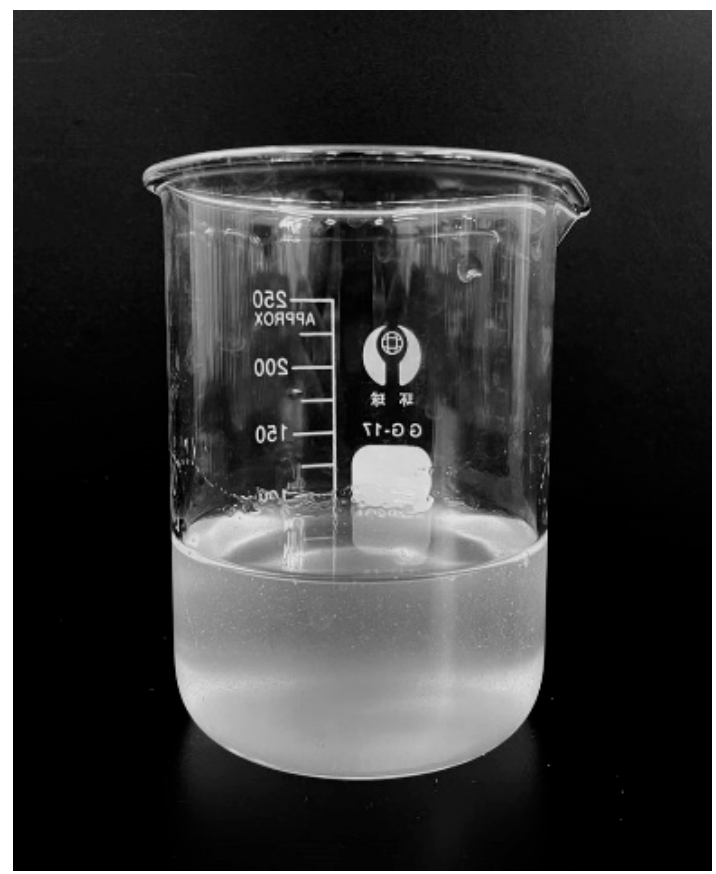

Figure 3. The base fluid of JK101 guar gum (0.45 wt.\%). 
Table 2. Base fluid viscosity test at different temperatures.

\begin{tabular}{cc}
\hline Temperature $\left({ }^{\circ} \mathbf{C}\right)$ & Apparent Viscosity $(\mathbf{m P a} \cdot \mathbf{s})$ \\
\hline 22.5 & 60.2 \\
31.2 & 49.8 \\
49.7 & 37.6 \\
62.6 & 21.4 \\
95.3 & 16.3 \\
106.4 & 12.6 \\
110.7 & 10.2 \\
\hline
\end{tabular}

\subsubsection{Chelating Agent}

In this paper, the complexometric titration method was mainly used to solve the crosslinking problem of high-salinity flowback water. The key concept of this method is masking the harmful metal cations. After the chelating agent dissolves in water, the negatively charged molecular chain generated by ionization interacts with the high-valence metal cations to produce a chelate, which prevents the metal cations from reacting with the thickener and alkali. The currently known chelating agents are mainly divided into inorganic, organic carboxylic acid, organic phosphoric acid, and amino carboxylic acid chelating agents [28]. In this study, organic carboxylic acid chelating agent CA-1, amino carboxylic acid chelating agent $\mathrm{CA}-3$, and organophosphate chelating agent CA-5 were considered for performance evaluation.

Through complexometric titration experiments, the volume of $\mathrm{MgCl}_{2}$ and $\mathrm{CaCl}_{2}$ solution consumed by three kinds of $5 \mathrm{~mL} 5 \mathrm{wt} . \%$ chelating agent solution were obtained, and the results are shown in Table 3. According to the results, the chelation values of the three chelating agents (i.e., CA-1, CA-3, and CA-5) were calculated through the above Equation (1) and are shown in Table 4. Among them, the chelating ability of CA-5 was significantly better than that of CA-1 and CA-3 for $\mathrm{Mg}^{2+}$ and $\mathrm{Ca}^{2+}$ at room temperature. Thus, CA-5 was preferred as the optimal chelating agent to be used in this experimental study, and the dosage of the chelating agent addition was further optimized. Additionally, according to the chelation value of CA-5, it can be calculated that for $1 \mathrm{~mol} \mathrm{Ca}^{2+}$ to be chelated, $4.95 \mathrm{~mol}$ chelating agent was required. Similarly, for $1 \mathrm{~mol} \mathrm{Mg}{ }^{2+}$ to be chelated, $4.54 \mathrm{~mol}$ chelating agent was required. Overall, the chelating ratio of the CA-5 chelating agent to $\mathrm{Ca}^{2+}$ and $\mathrm{Mg}^{2+}$ was approximately 1:5, respectively. The chelation ratio results obtained in this experiment are slightly larger than the conventional data, such as the most common $1: 2$ or 1:3 ratios. This may be related to the type of chelating agent and the test environment. The chelation constants of various chelating agents are different, and the temperature as well as the $\mathrm{pH}$ value of the solution will significantly affect the stability of the chelation products.

Table 3. Consumption volume of $\mathrm{MgCl}_{2}$ and $\mathrm{CaCl}_{2}$ by $5 \mathrm{~mL}$ chelating agent solution with a mass concentration of $5 \mathrm{wt} . \%$ at the end of titration.

\begin{tabular}{ccc}
\hline \multirow{2}{*}{ Type } & \multicolumn{2}{c}{ Consumption Volume at the End of Titration $\mathbf{( m L )}$} \\
\cline { 2 - 3 } & $\mathbf{M g C l}_{\mathbf{2}} \mathbf{( 1 \mathbf { ~ m o l } / \mathbf { L } )}$ & $\mathbf{C a C l}_{\mathbf{2}} \mathbf{( 1 \mathbf { ~ m o l } / \mathbf { L } )}$ \\
\hline $5 \mathrm{~mL}, 5 \mathrm{wt} \%, \mathrm{CA}-1$ & 0.9 & 0.8 \\
$5 \mathrm{~mL}, 5 \mathrm{wt} . \%, \mathrm{CA}-3$ & 0.7 & 0.6 \\
$5 \mathrm{~mL}, 5 \mathrm{wt} \%$, CA-5 & 5.5 & 6.0 \\
\hline
\end{tabular}


Table 4 . The chelating values of three chelating agents.

\begin{tabular}{cccc}
\hline \multirow{2}{*}{ Ion Type } & \multicolumn{3}{c}{ Chelation Values of $\mathbf{C a}^{2+}$ and $\mathbf{M g}^{2+}(\mathbf{m g} / \mathbf{m L})$} \\
\cline { 2 - 4 } & CA-1 & CA-3 & CA-5 \\
\hline $\mathrm{Mg}^{2+}$ & 86.4 & 67.2 & 528 \\
$\mathrm{Ca}^{2+}$ & 128 & 96 & 960 \\
\hline
\end{tabular}

\section{(1) Dosage optimization}

A combination of theoretical calculations and experimental methods were used to optimize the dosage of the CA- 5 chelating agent. The JK101 guar gum base liquid prepared with high-salinity water appeared to stratify and become turbid under weak alkaline conditions. This phenomenon can be avoided by adding the optimal dosage of the chelating agent.

From Table 1, the contents of $\mathrm{Ca}^{2+}$ and $\mathrm{Mg}^{2+}$ in water sample $\mathrm{E}$ were 458.5 and $2309 \mathrm{mg} / \mathrm{L}$, respectively. Thus, the theoretical contents of $\mathrm{Ca}^{2+}$ and $\mathrm{Mg}^{2+}$ in $100 \mathrm{~mL}$ of water sample E were 45.85 and $230.9 \mathrm{mg}$, respectively. According to Table 4, each $1 \mathrm{~mL}$ of CA-5 enabled chelate of $960 \mathrm{Ca}^{2+}$ and $528 \mathrm{mg} \mathrm{Mg}^{2+}$. Hence, $0.0478 \mathrm{~mL} \mathrm{CA}-5$ was required to chelate $\mathrm{Ca}^{2+}$ and $0.437 \mathrm{~mL} \mathrm{CA}-5$ to chelate $\mathrm{Mg}^{2+}$ in $100 \mathrm{~mL}$ of water sample E. The CA-5 chelating agent with a mass concentration of $50 \mathrm{wt} . \%$ was used for the optimization experiment. Therefore, the mass of the CA- 5 solution required to chelate all of the $\mathrm{Ca}^{2+}$ and $\mathrm{Mg}^{2+}$ in the $100 \mathrm{~mL}$ of water sample E was $(0.0478+0.437) / 50 \%=0.9696 \mathrm{~g}$. To facilitate subsequent experiments, the dosage of the CA- 5 chelating agent in water sample $\mathrm{E}$ was determined to be $1 \mathrm{wt} . \%$.

The experimental steps of the chelating agent dosage optimization were as follows: add the same amount of water sample $\mathrm{E}$ into four beakers, followed by unequal dosage of CA-5 chelating agents with a mass concentration of $50 \mathrm{wt} . \%$, forming systems with concentrations of $0.6 \mathrm{wt} . \%, 0.8 \mathrm{wt} . \%, 1.0 \mathrm{wt} . \%$, and $1.2 \mathrm{wt} . \%$, respectively. Under highspeed stirring, slowly add JK101 to four beakers and stir continuously for $15 \mathrm{~min}$ to form guar gum base fluid with a mass concentration of $0.45 \mathrm{wt} . \%$. Finally, add equal dosages of the YC-150 regulator and YZ-1 crosslinker to the four guar gum base fluids to observe their crosslinking performance. The experimental results showed that the crosslinked gel fracturing fluids in the four beakers had different degrees of crosslinking effect. Among them, the first two groups (i.e., chelating agent concentrations of 0.6 and $0.8 \mathrm{wt} . \%$ ) showed undesired crosslinking effects. This was mainly because in the process of adding the YC-150 regulator, the excess $\mathrm{Ca}^{2+}$ and $\mathrm{Mg}^{2+}$ in the base fluid reacted with hydroxide to form a white flocculent precipitate (Figure 4), which had a harmful effect on the subsequent crosslinking agent. Although there was a significant increase in viscosity, the formed gel fracturing fluid was too flexible to be picked and hung (Figure 5a), indicating the dosage of the chelating agent was insufficient. The latter two groups (i.e., chelating agent concentrations of 1.0 and $1.2 \mathrm{wt} . \%$ ) had excellent crosslinking effects. Sufficient dosages of chelating agent can adequately shield the $\mathrm{Ca}^{2+}$ and $\mathrm{Mg}^{2+}$ in the solution and both can achieve perfect hanging effects (Figure $5 \mathrm{~b}$ ). This verified the feasibility of the theoretical calculation results; thus, the optimal CA-5 dosage for water sample E was $1.0 \mathrm{wt} . \%$ in this study. 


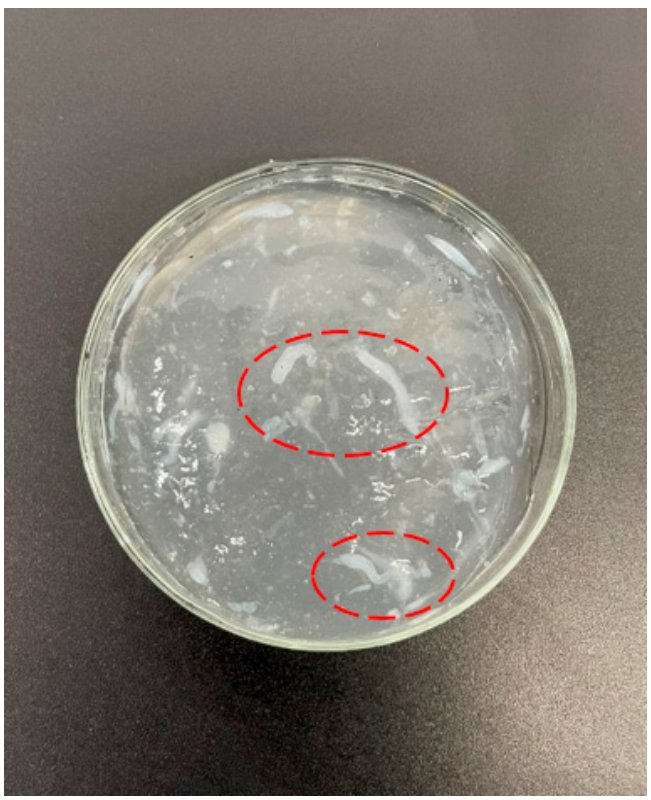

Figure 4. White flocculent precipitate formed.

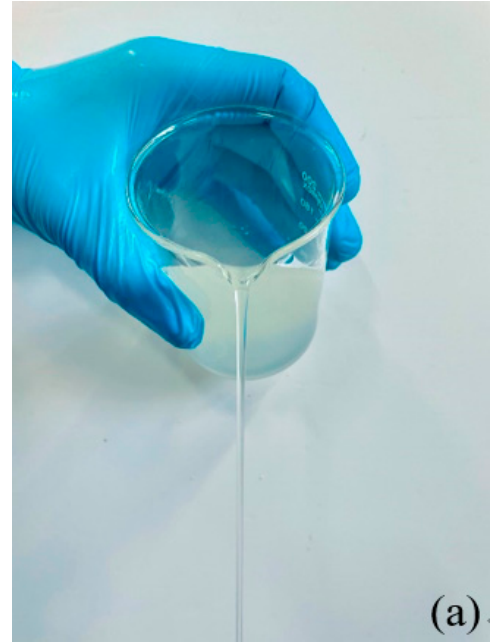

Figure 5. Effect of chelating agent dosage on crosslinking:

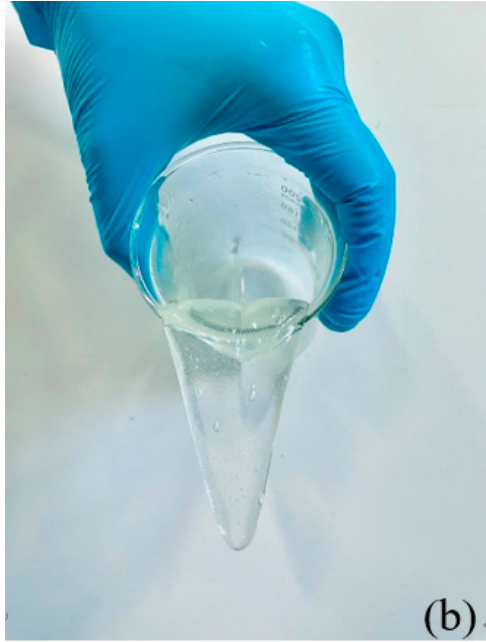

(a) insufficient dosage; (b) sufficient dosage.

\section{(2) Relationship between chelating agent dosage and $\mathrm{Ca}^{2+} / \mathrm{Mg}^{2+}$ concentration}

The above studies have shown that the presence of $\mathrm{Ca}^{2+}$ and $\mathrm{Mg}^{2+}$ in high-salinity water has negative impacts on the swelling and thickening properties of thickeners, while chelating agents can effectively inhibit the adverse effects of high-valence metal ions [28]. Based on the above research, five water samples were used to explore the relationship between the dosage of chelating agent (CA-5) and the total molar concentrations of $\mathrm{Ca}^{2+}$ and $\mathrm{Mg}^{2+}$ in high-salinity water, providing an experimental basis for subsequent related studies.

A combination of theoretical calculations and experimental methods were used to explore the relationship between the dosage of CA-5 with different total molar concentrations of $\mathrm{Ca}^{2+}$ and $\mathrm{Mg}^{2+}$ as shown in Figure 6. From the figure, we can see that there was a good linear relationship between different concentrations of chelating agent (CA-5) dosages and the total molar concentrations of $\mathrm{Ca}^{2+}$ and $\mathrm{Mg}^{2+}$, and the linear equations at different concentrations were obtained by fitting. According to the fitted linear equation, it can be further calculated that the chelation ratio of the CA-5 chelating agent to $\mathrm{Ca}^{2+}$ and $\mathrm{Mg}^{2+}$ was 1:1.46, which is in good agreement with the above experimental test results. To 
verify the accuracy of the fitting equation, we further conducted several experiments with $\mathrm{Ca}^{2+}$ and $\mathrm{Mg}^{2+}$ at $0.02 \mathrm{~mol} / \mathrm{L}, 0.04 \mathrm{~mol} / \mathrm{L}, 0.06 \mathrm{~mol} / \mathrm{L}, 0.08 \mathrm{~mol} / \mathrm{L}$, and $0.10 \mathrm{~mol} / \mathrm{L}$. The obtained data are the purple verification points marked in the Figure 6 , in line with the fitting formula under different concentrations. This chart can be directly applied to the calculation of the CA- 5 dosage in other flowback water samples with different total molar concentrations of $\mathrm{Ca}^{2+}$ and $\mathrm{Mg}^{2+}$. Moreover, based on the above study, we established a guide to the use of a chelating agent dosage criterion. Firstly, calculate the chelating value of the chelating agent by complexometric titration experiments. Then, through theoretical calculation and experimental verification methods, the optimal dosages for flowback water with different salinities are obtained. Finally, a chart on the relationship between the dosage of the chelating agent and the salinity of the water is formed, which can be directly used to guide the application for the flowback and produced water with different salinities.

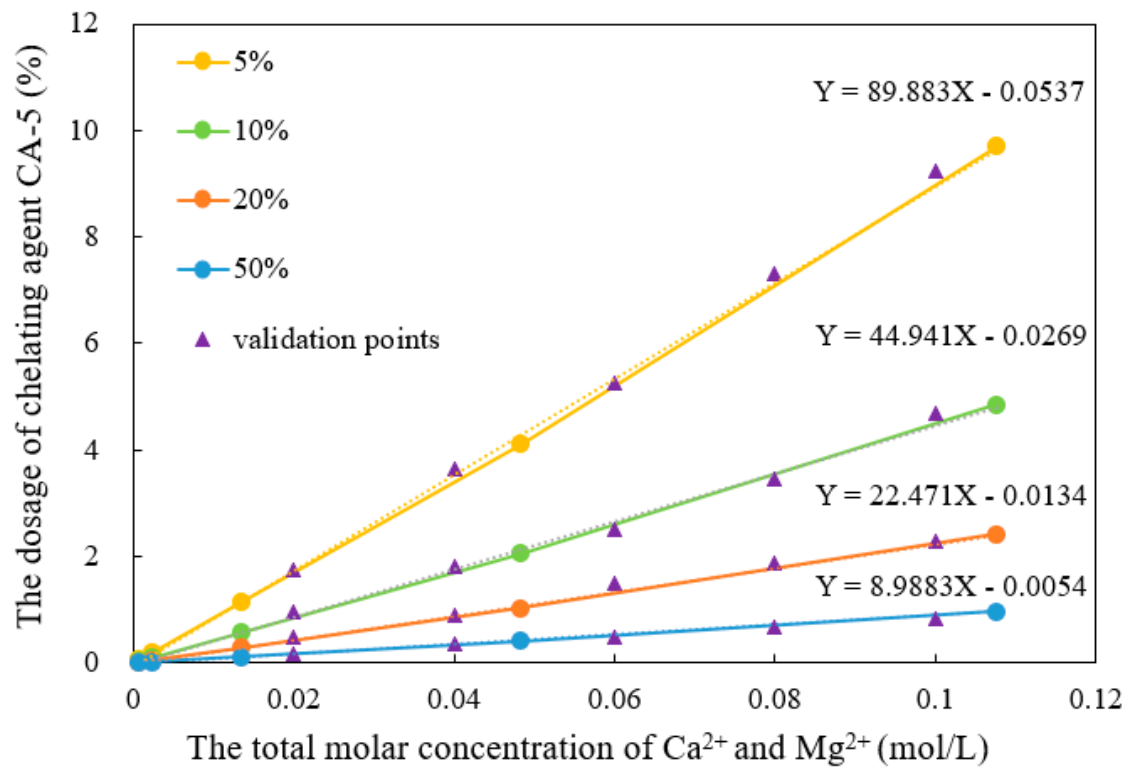

Figure 6. The relationship between the dosage of the chelating agent (CA-5) and the total molar concentration of $\mathrm{Ca}^{2+}$ and $\mathrm{Mg}^{2+}$.

\subsubsection{Crosslinker}

\section{(1) Dosage optimization}

The dosage optimization of the organic boron crosslinker, YZ-1, was evaluated by the pick-and-hang experiment for the fracturing fluid system. Firstly, the $\mathrm{pH}$ value of JK101 base fluid with a concentration of $0.45 \mathrm{wt} \%$ was adjusted to 11 12 with the YC-150 regulator, because the organic boron crosslinker had the best crosslinking effect in an alkaline environment. Then, 0.35 wt. $\%, 0.40$ wt. $\%, 0.45$ wt. $\%, 0.50$ wt. $\%, 0.55$ wt. $\%$, and $0.60 \mathrm{wt} . \%$ crosslinker YZ-1 were added to the base fluid in proportion, and the crosslinking and hanging effects of the formed gel fracturing fluids were recorded after fully stirring. As shown in Table 5, the system shows different crosslinking effects after adding regulator and crosslinker to the base solution. The hanging performance was gradually enhanced with the increasing dosage of crosslinker as shown in Figure 7. When the dosage of the YZ-1 crosslinker exceeded $0.55 \mathrm{wt} \%$, the formed gel fracturing fluid system presented the best crosslinking and hanging performances. Considering the cost and other factors, the optimal dosage of the organic boron crosslinker YZ-1 was $0.55 \mathrm{wt} . \%$. 
Table 5. Crosslinking and hanging performances of the fracturing fluid system.

\begin{tabular}{cccc}
\hline Group & $\begin{array}{c}\text { Dosage of YZ-1 } \\
\text { Crosslinker }(w t . \%)\end{array}$ & $\begin{array}{c}\text { Crosslinking } \\
\text { Performance }\end{array}$ & Hanging Performance \\
\hline 1 & 0.35 & Weak & Unable \\
2 & 0.40 & Weak & Unable \\
3 & 0.45 & Weak & Slight \\
4 & 0.50 & Strong & Slight \\
5 & 0.55 & Strong & Complete \\
6 & 0.60 & Strong & Complete \\
\hline
\end{tabular}
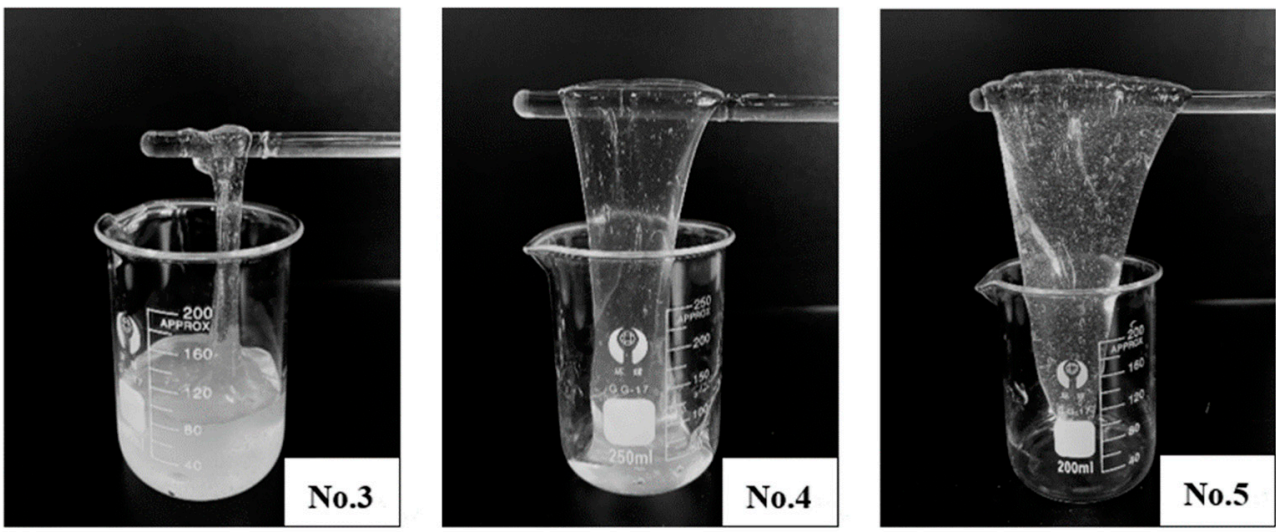

Figure 7. Comparison of different crosslinking and hanging performances. No. 3 shows the experimental phenomenon of Group 3 in the Table 5, and No. 4 indicates Group 4 and and No. 5 indicates Group 5.

\section{(2) Delayed crosslinking}

The delayed crosslinking performance of the fracturing fluid can effectively reduce the frictional pressure difference during wellbore flow. Since the change of $\mathrm{pH}$ has a certain effect on the hydrolysis of boric acid in the organic boron crosslinker and can delay the crosslinking, this study further explored the effect of $\mathrm{pH}$ on the delayed crosslinking performance of the new crosslinker, YZ-1. The specific experimental steps are as follows: (1) prepare six parts of JK101 guar gum base fluid with a mass concentration of $0.45 \mathrm{wt} . \%$; (2) add unequal amounts of the YC-150 regulator to adjust the $\mathrm{pH}$ value of the base fluid to $8,9,10,11,12$, and 13; (3) under stirring, add the crosslinker YZ-1 to each of them at a concentration of $0.55 \mathrm{wt} . \%$. The crosslinking time of each group are recorded in Table 6. Figure 8 shows the relationship curve of crosslinking time as a $\mathrm{pH}$ value change of base fluid. The figure shows that the crosslinking time increases with the $\mathrm{pH}$ value of the system, ranging from 72 to $276 \mathrm{~s}$, which can meet the requirements of most field fracturing operations.

Table 6. Crosslinking time of the fracturing fluid under different $\mathrm{pH}$ conditions.

\begin{tabular}{ccc}
\hline Dosage of YC-150 Regulator (wt.\%) & pH Value & Crosslinking Time (s) \\
\hline 0.32 & 7 & 72 \\
0.42 & 8 & 94 \\
0.51 & 9 & 143 \\
0.61 & 10 & 174 \\
0.70 & 11 & 226 \\
0.80 & 12 & 257 \\
0.90 & 13 & 268 \\
\hline
\end{tabular}




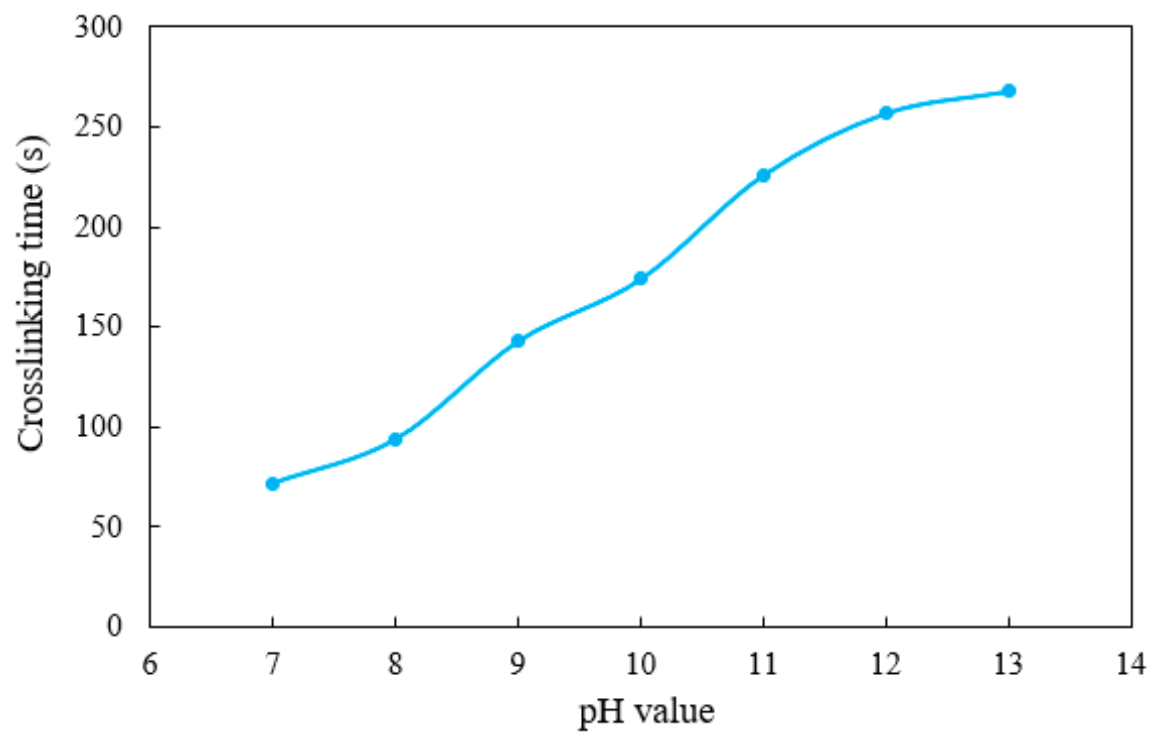

Figure 8. Curve of crosslinking time versus $\mathrm{pH}$ value.

\subsubsection{Determination of Fracturing Fluid Formula}

After the above single-agent screening and evaluation experiments, the highest salinity water sample, E, was selected as an example to prepare the fracturing fluid. The determined formula of the novel guar fracturing fluid prepared with flowback water was water sample $\mathrm{E}+1 \mathrm{wt.} \%$ chelating agent CA-5 (50 wt. $\%)+0.45$ wt. $\%$ JK101 guar gum +0.80 wt. $\%$ regulator YC-150 + $0.55 \mathrm{wt} . \%$ crosslinker YZ-1.

\subsection{Performance Evaluation of the Fracturing Fluid}

\subsubsection{Temperature and Shear Resistance Performance}

The novel guar fracturing fluid system was prepared according to the above formula. An HAAKE rheometer was used to measure the apparent viscosity of the fracturing fluid after shearing for $80 \mathrm{~min}$ under $150^{\circ} \mathrm{C}$ and $170 \mathrm{~s}^{-1}$ condition. The obtained rheological curve of apparent viscosity varied with temperature as shown in Figure 9. As can be seen from the figure, the final viscosity of the high-salinity resistant fracturing fluid remained above $50 \mathrm{mPa} \cdot \mathrm{s}$. This means the prepared fracturing fluid still had a good sand-carrying performance after high-temperature shearing, which could meet the requirements for most wellsite operations.

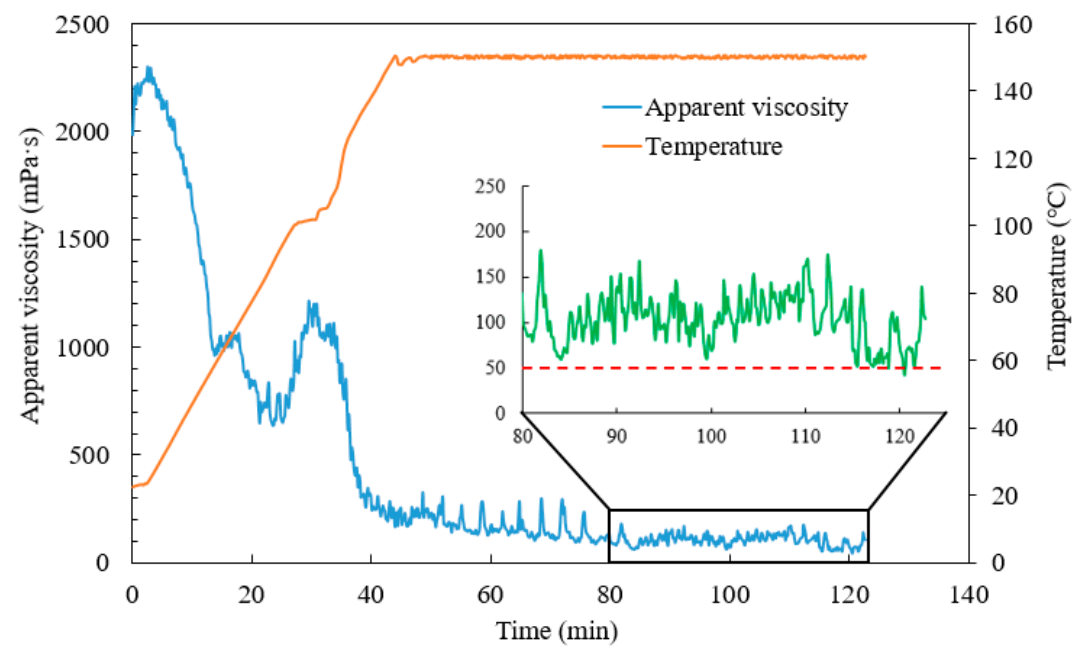

Figure 9. The rheological curve of the apparent viscosity varied with the temperature. 


\subsubsection{Friction Reduction Performance}

The $8 \mathrm{~mm}$ diameter pipeline in the loop friction test system was used for the friction reduction performance test, whereas the tubing diameter used in most field fracturing operations is 3.5 inches (i.e., $75.9 \mathrm{~mm}$ ). From knowledge of fluid mechanics, we know that the flow velocity of the same displacement fluid in different pipe diameters is different, and the friction reduction effect of fracturing fluid is closely related to the linear velocity. Therefore, we need to convert the displacement parameters to linear velocity, so that the laboratory experiment results match with those of field practice. Linear velocity was calculated as the fluid displacement divided by the cross-sectional area of the oil pipe, namely:

$$
v=\frac{Q}{\rho \pi r^{2}}
$$

In the equation, $v$ is the linear velocity, $\mathrm{m} / \mathrm{s} ; Q$ is the displacement, $\mathrm{kg} / \mathrm{h} ; \rho$ is the density, $\mathrm{kg} / \mathrm{m}^{3} ; r$ is the oil pipe radius, $m$. Based on the equation, linear velocity was used as a transition variable to associate the indoor test displacement with the field fracturing displacement as shown in Table 7. With the highest displacement (i.e., $2500 \mathrm{~kg} / \mathrm{h}$ ) of the indoor screw pump, the linear velocity in the test pipeline reached $13.80 \mathrm{~m} / \mathrm{s}$, and the corresponding field construction displacement was only $3.70 \mathrm{~m}^{3} / \mathrm{min}$. From the curve of friction reduction rate (Figure 10), it was clear that with the increase in linear velocity, the friction reduction rate of the guar gum base fluid presented a gradually increasing trend. That is, the friction reduction effect of the base fluid was relatively better under high flow rate conditions. The maximum friction reduction rate of $0.45 \mathrm{wt} . \%$ JK101 based fluid reached $73.2 \%$, while the maximum displacement during fracturing in the field was usually greater than $3.70 \mathrm{~m}^{3} / \mathrm{min}$; thus, the actual friction reduction rate in the field is predicted to exceed $73.2 \%$.

Table 7. Summary table of displacement, linear velocity, and friction reduction rate.

\begin{tabular}{|c|c|c|c|c|c|c|c|c|c|c|}
\hline Lab test displacement $(\mathrm{kg} / \mathrm{h})$ & 250 & 500 & 750 & 1000 & 1250 & 1500 & 1750 & 2000 & 2250 & 2500 \\
\hline Linear velocity (m/s) & 1.38 & 2.76 & 4.14 & 5.52 & 6.90 & 8.28 & 9.66 & 11.04 & 12.42 & 13.80 \\
\hline Field fracturing displacement $\left(\mathrm{m}^{3} / \mathrm{min}\right)$ & 0.37 & 0.74 & 1.11 & 1.48 & 1.85 & 2.22 & 2.59 & 2.96 & 3.33 & 3.70 \\
\hline Friction reduction rate $(\%)$ & 38.7 & 47.4 & 56.9 & 62.5 & 65.6 & 67.2 & 69.8 & 70.9 & 71.9 & 72.6 \\
\hline
\end{tabular}

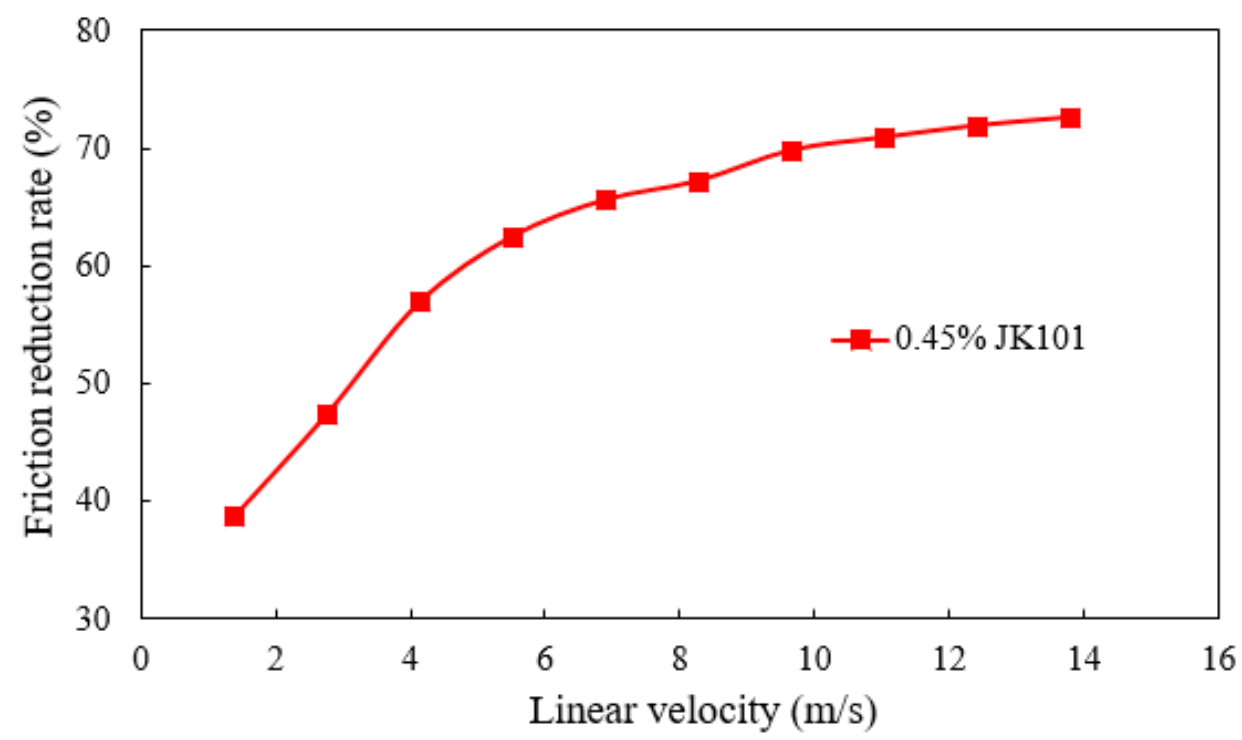

Figure 10. The friction reduction rate varied with the linear velocity. 


\subsubsection{Gel-Breaking Performance}

Once the highly viscous sand-carrying fluid completes the migration and settlement of the proppant, a gel breaker is required to break up the formed guar fracturing fluid and reduce its viscosity so that it can be easily re-discharged from the fractures. Commonly used gel-breaking methods include oxidative breakage, potential acid breakage, and biological enzyme breakage [27].

The results of the gel-breaking tests at different temperatures are shown in Figure 11. The viscosity of the fluid sharply decreased after adding ammonium persulfate breaker. The temperature also had a serious impact on the viscosity. When the temperature reached $150{ }^{\circ} \mathrm{C}$, the apparent viscosity of the gel-breaking fluid was less than $5 \mathrm{mPa} \cdot \mathrm{s}$ within $5 \mathrm{~h}$. It fully met the viscosity requirements of field operations for the gel-breaking performance of fracturing fluid. However, the final viscosity of the fluid was $17.6 \mathrm{mPa} \cdot \mathrm{s}$ at a temperature of $90{ }^{\circ} \mathrm{C}$. Even if the dosage of the gel breaker increased from 0.05 to $0.08 \mathrm{wt} . \%$, the final fluid viscosity was still more than $5 \mathrm{mPa} \cdot \mathrm{s}$. Further examination revealed that temperature was the key factor, and a higher temperature tended to bring about a lower final viscosity.

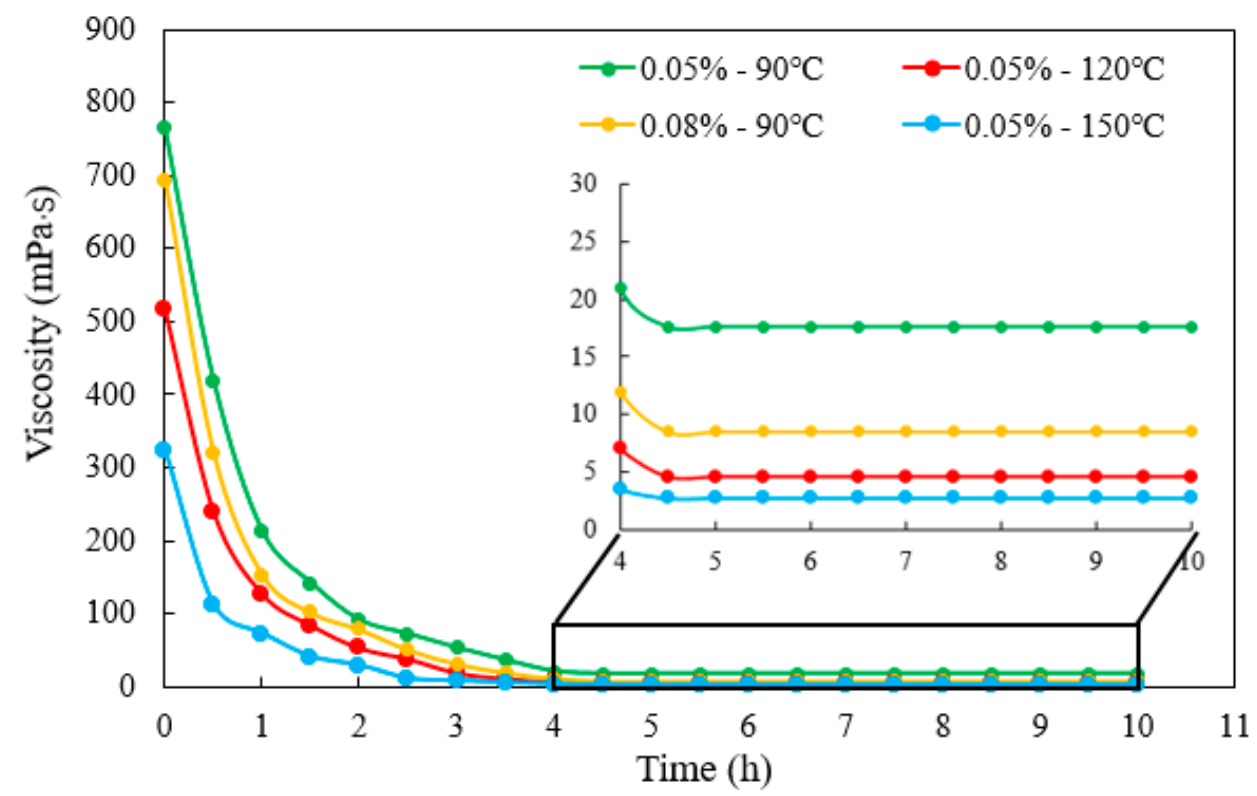

Figure 11. Gel-breaking performances at different temperatures.

The residue contents of gel-breaking fluid at different gel-breaking conditions are listed in Table 8. When the dosage of ammonium persulfate was $0.05 \mathrm{wt} . \%$ with a temperature of $90{ }^{\circ} \mathrm{C}$, the calculated residue content was $634 \mathrm{mg} / \mathrm{L}$, which is much higher than the international standard of $550 \mathrm{mg} / \mathrm{L}$. The residue contents in the other three breaking experiments were relatively low, which greatly reduced the damage by fracturing fluid to the reservoir and met the requirements of field hydraulic fracturing operations.

Table 8. Gel-breaking fluid residue tests.

\begin{tabular}{ccccccc}
\hline Entry & $\begin{array}{c}\text { Thickener } \\
\text { Concentration }\end{array}$ & $\begin{array}{c}\text { Crosslinker } \\
\text { Concentration }\end{array}$ & $\begin{array}{c}\text { Ammonium } \\
\text { Persulfate } \\
\text { Concentration }\end{array}$ & $\begin{array}{c}\text { Gel-Breaking } \\
\text { Temperature }\end{array}$ & $\begin{array}{c}\text { Gel-Breaking } \\
\text { Time }\end{array}$ & $\begin{array}{c}\text { Residue } \\
\text { Content }\end{array}$ \\
\hline$\# 1$ & $0.45 \mathrm{wt} . \%$ & $0.55 \mathrm{wt} \%$ & $0.05 \mathrm{wt} . \%$ & $90^{\circ} \mathrm{C}$ & $5 \mathrm{~h}$ & $634 \mathrm{mg} / \mathrm{L}$ \\
$\# 2$ & $0.45 \mathrm{wt} . \%$ & $0.55 \mathrm{wt} . \%$ & $0.08 \mathrm{wt} . \%$ & $90^{\circ} \mathrm{C}$ & $5 \mathrm{~h}$ & $278 \mathrm{mg} / \mathrm{L}$ \\
$\# 3$ & $0.45 \mathrm{wt} \%$ & $0.55 \mathrm{wt} \%$ & $0.05 \mathrm{wt} \%$ & $120^{\circ} \mathrm{C}$ & $5 \mathrm{~h}$ & $326 \mathrm{mg} / \mathrm{L}$ \\
$\# 4$ & $0.45 \mathrm{wt} . \%$ & $0.55 \mathrm{wt} . \%$ & $0.05 \mathrm{wt} . \%$ & $150^{\circ} \mathrm{C}$ & $5 \mathrm{~h}$ & $197 \mathrm{mg} / \mathrm{L}$ \\
\hline
\end{tabular}




\subsubsection{Core Damage Performance}

To evaluate the formation damage of the novel guar fracturing fluid, core damage tests were conducted, and the results are shown in Table 9. Herein, the gel-breaking fluid used for the core damage test was entry \#4, which had the lowest residue content as shown in Table 8. The average damage rate of the three natural cores with different permeabilities was $25.67 \%$, which is less than the industrial standard of $30 \%$. The result indicates that the novel fracturing fluid system proposed in this study has less damage to formation and is suitable for the hydraulic stimulation.

Table 9. Results of the core damage tests.

\begin{tabular}{ccccc}
\hline Core No. & $\begin{array}{c}\text { Permeability } \\
\text { before Damage } \\
\mathbf{K}_{\mathbf{1}}, \mathbf{1 0}^{-\mathbf{3}} \boldsymbol{\mu \mathbf { m }}^{\mathbf{2}}\end{array}$ & $\begin{array}{c}\text { Permeability } \\
\text { after Damage } \\
\mathbf{K}_{\mathbf{2}} \mathbf{1 0}^{-\mathbf{3}} \boldsymbol{\mu \mathbf { m } ^ { \mathbf { 2 } }}\end{array}$ & $\begin{array}{c}\text { Core Damage } \\
\text { Rate, \% }\end{array}$ & $\begin{array}{c}\text { Average } \\
\text { Damage } \\
\text { Rate, \% }\end{array}$ \\
\hline S-1 & 0.084 & 0.061 & 27.38 & \\
S-2 & 0.167 & 0.119 & 28.74 & 25.67 \\
S-3 & 0.359 & 0.284 & 20.89 & \\
\hline
\end{tabular}

\section{Conclusions}

In order to economically and efficiently utilize flowback and produced water with different salinities, a complex masking method was applied to deal with the harmful effects of $\mathrm{Ca}^{2+}$ and $\mathrm{Mg}^{2+}$ on crosslinking. The relationship between the dosage of the chelating agent and the total molar concentrations of $\mathrm{Ca}^{2+}$ and $\mathrm{Mg}^{2+}$ was further determined using theoretical calculations and experimental methods and, thus, a reference chart was formed. By optimizing the dosage of various additives, including thickeners, crosslinkers, and $\mathrm{pH}$ regulators, a novel guar fracturing fluid was finally obtained. Then, the comprehensive performance of this novel fluid system prepared by the highest-salinity flowback water was evaluated. The novel fracturing fluid featured good temperature and shear resistance, low friction, and less damage to formation. Through the above research, the main conclusions are as follows:

1. For flowback and produced water with different salinities, a complex masking method can effectively solve the crosslinking problem caused by high-valence metal ions. Among the three chelating agents, the organophosphate CA- 5 chelating agent had the best chelating effect on $\mathrm{Ca}^{2+}$ and $\mathrm{Mg}^{2+}$;

2. There was a good linear relationship between the dosage of the chelating agent and the total molar concentrations of $\mathrm{Ca}^{2+}$ and $\mathrm{Mg}^{2+}$ in the solution. The main mechanism was that the chelating agents formed complexes with $\mathrm{Ca}^{2+}$ and $\mathrm{Mg}^{2+}$ at a chelation ratio of 1:5;

3. A novel organic boron crosslinker with temperature and salt resistance was synthesized. Crosslinking and hanging tests were carried out to optimize the dosage of the crosslinker, and the formed gel fracturing fluid exhibited various crosslinking strengths at different dosages. The designed crosslinker could also realize delayed crosslinking, and the time could be flexibly adjusted according to the $\mathrm{pH}$ value of base fluid;

4. Taking the highest salinity water sample as an example, the novel guar fracturing fluid was successfully formulated. Its composition was water sample E $+1 \mathrm{wt} . \%$ CA-5 (50 wt. \%) chelating agent + 0.45 wt. $\%$ JK101 guar gum +0.80 wt. $\%$ YC-150 regulator $+0.55 \mathrm{wt} . \% \mathrm{YZ}-1$ crosslinker. The novel guar fracturing fluid showed an excellent temperature and shear performance. The final apparent viscosity remained above $50 \mathrm{mPa} \cdot \mathrm{s}$ after shearing for $80 \mathrm{~min}$ at $150{ }^{\circ} \mathrm{C}$ and $170 \mathrm{~s}^{-1}$. The maximum friction reduction rate of the base fluid measured by a laboratory loop friction test reach $73.2 \%$. Ammonium persulfate breaker quickly broke down the gel fracturing fluid. The viscosity of gel-breaking fluid was less than $5 \mathrm{mPa} \cdot \mathrm{s}$ within $5 \mathrm{~h}$ at $150^{\circ} \mathrm{C}$, and the lowest residue content was only $197 \mathrm{mg} / \mathrm{L}$, which is far below international 
standards. The average damage rate of the gel-breaking fluid was $25.67 \%$, indicating the proposed fracturing fluid was less damaging to formation.

5. This study solves the crosslinking problem caused by high-valence metal ions. It can optimize the most economic and effective chelating agent dosage for flowback and produced water with different salinities, providing a research basis for the reuse of flowback water.

Author Contributions: Conceptualization, F.Z.; methodology, Y.L. and E.Y.; validation, X.R., H.X., and H.B.; formal analysis, X.R.; investigation, H.B.; resources, F.Z.; data curation, Y.L.; writingoriginal draft preparation, H.X.; writing-review and editing, E.Y. and H.X.; visualization, H.X.; supervision, F.Z. and E.Y. All authors have read and agreed to the published version of the manuscript.

Funding: This research received no external funding.

Data Availability Statement: The data are available upon request.

Acknowledgments: This research was financially supported by the National Natural Science Foundation of China (Grant Nos. 52004306 and 52174045), the Strategic Cooperation Technology Projects of CNPC and CUPB (Grant Nos. ZLZX2020-01 and ZLZX2020-02), and the National Science and Technology Major Projects of China (Grant Nos. 2016ZX05030005 and 2016ZX05051003).

Conflicts of Interest: The authors declare no conflict of interest.

\section{References}

1. Liu, Y.-G.; Hou, J.; Zhao, H.-F.; Liu, X.-Y.; Xia, Z.-Z. A method to recover natural gas hydrates with geothermal energy conveyed by $\mathrm{CO}_{2}$. Energy 2018, 144, 265-278. [CrossRef]

2. Zhou, F.-J.; Su, H.; Liang, X.-Y.; Meng, L.-F.; Yuan, L.-S.; Li, X.-H.; Liang, T.-B. Integrated hydraulic fracturing techniques to enhance oil recovery from tight rocks. Petrol. Explor. Dev. 2019, 46, 1065-1072. [CrossRef]

3. Wang, W.-Y.; Pang, X.-Q.; Chen, Z.-X.; Chen, D.-X.; Zheng, T.-Y.; Luo, B.; Li, J.; Yu, R. Quantitative prediction of oil and gas prospects of the Sinian-Lower Paleozoic in the Sichuan Basin in central China. Energy 2019, 174, 861-872. [CrossRef]

4. Harman, C.; McDonald, M.; Short, P.; Ott, W. Silica gel fracturing fluids an alternative to guar systems that allows the use of west Texas produced water. In Proceedings of the SPE Hydraulic Fracturing Technology Conference and Exhibition, Virtual Conference, 4-6 May 2021.

5. Clark, C.-E.; Veil, J.-A. Produced Water Volumes and Management Practices in the United States; Argonne National Lab (ANL): Argonne, IL, USA, 2009.

6. Gregory, K.-B.; Vidic, R.-D.; Dzombak, D.-A. Water management challenges associated with the production of shale gas by hydraulic fracturing. Elements 2011, 7, 181-186. [CrossRef]

7. Whistler, R.-L.; BeMi, J.-N. Industrial Gums: Polysaccharides and Their Derivatives; Elsevier: Amsterdam, The Netherlands, 2012.

8. Muhammad, S.-K.; Mohammed, M.; Elkatatny, S. Development of chelating agent-based polymeric gel system for hydraulic fracturing. Energies 2018, 11, 1663.

9. Al-Muntasheri, G.-A. A critical review of hydraulic-fracturing fluids for moderate-to ultralow-permeability formations over the last decade. SPE Prod. Oper. 2014, 29, 243-260. [CrossRef]

10. Jennings, A.-R. Fracturing fluids-then and now. J. Petrol. Technol. 1996, 48, 604-610. [CrossRef]

11. Cheng, Y.; Brown, K.-M.; Prud'homme, R.-K. Characterization and intermolecular interactions of hydroxypropyl guar solutions. Biomacromolecules 2002, 3, 456-461. [CrossRef] [PubMed]

12. Banerjrr, P.; Mukherjee, I.; Bhattacharya, S.; Datta, S.; Moulik, S.-P.; Sarkar, D. Sorption of water vapor, hydration, and viscosity of carboxymethylhydroxypropyl guar, diutan, and xanthan gums, and their molecular association with and without salts $\left(\mathrm{NaCl}, \mathrm{CaCl}_{2}, \mathrm{HCOOK}, \mathrm{CH}_{3} \mathrm{COONa},(\mathrm{NH} 4)_{2} \mathrm{SO}_{4}\right.$ and $\left.\mathrm{MgSO}_{4}\right)$ in aqueous solution. Langmuir 2009, 25, 11647-11656. [CrossRef] [PubMed]

13. Gittings, M.-R.; Cipelletti, L.; Trappe, V.; Weitz, D.-A.; Ln, M.; Lal, J. The effect of solvent and ions on the structure and rheological properties of guar solutions. J. Phys. Chem. A 2001, 105, 9310-9315. [CrossRef]

14. Li, Y.; Guan, B.-S.; Xu, Y. The research of complexant about using high-salinity water for fracturing fluid. Sci. Technol. Eng. 2016, $16,175-180$.

15. Ali, S.-A.; Pickering, W.-M.; Sketchler, B.-C.; Powell, R.-J; Vitthal, S. Offshore frac packs benefit from seawater-based borate fluid. Oil Gas J. 1998, 96, 49-62.

16. Fedorov, A.; Carrasquilla, J.; Cox, A. Avoiding damage associated to produced water use in hydraulic fracturing. In Proceedings of the SPE International Symposium and Exhibition on Formation Damage Control, Lafayette, LA, USA, 26-28 February 2014.

17. LeBas, R.-A.; Sha, H.; Wayne, T.; Lord, P.; Luna, D. Development and use of high-TDS recycled produced water for crosslinkedgel-based hydraulic fracturing. In Proceedings of the SPE Hydraulic Fracturing Technology Conference, The Woodlands, TX, USA, 4-6 February 2013. 
18. Gupta, D.-V.; Carman, P.-S.; Venugopal, R.-A. Stable fracturing fluid for produced water applications. In Proceedings of the SPE Annual Technical Conference and Exhibition, San Antonio, TX, USA, 8-10 October 2012.

19. Bulat, D.; Chen, Y.; Graham, M.-K.; Marcinew, R.-P.; Adeogun, A.-S.; Sheng, J.; Abad, C. A faster cleanup, produced watercompatible fracturing fluid: Fluid designs and field case studies. In Proceedings of the SPE International Symposium and Exhibition on Formation Damage Control, Lafayette, LA, USA, 13-15 February 2008.

20. Elsarawy, A.-M.; Nasr-El-Din, H.-A.; Cawiezel, K.-E. The effect of chelating agents on the use of produced water in crosslinkedgel-based hydraulic fracturing. In Proceedings of the SPE Low Perm Symposium, Denver, CO, USA, 5-6 May 2016.

21. Taylor, K.-C.; Nasr-EI-Din, H.-A. A systematic study of iron control chemicals-part 2; Paper SPE 50772. In Proceedings of the International Symposium on Oilfield Chemistry, Houston, TX, USA, 16-19 February 1999.

22. Liu, Y.-T.; Guan, B.-S.; Liu, P.; Wang, L.-W.; Cui, W.-X. Research and field application of fracturing sequester. Chem. Reag. 2010, 32, 545-547.

23. Li, W.-W.; Wen, Z.; Bo, C.; Li, Y.-J.; Qiu, X.-H. $220{ }^{\circ} \mathrm{C}$ Ultra-temperature fracturing fluid in high pressure and high temperature reservoirs. In Proceedings of the Offshore Technology Conference Asia, Kuala Lumpur, Malaysia, 22-25 March 2016.

24. Huang, Q.; Liu, S.; Wang, G.; Wu, B.; Zhang, Y. Coalbed methane reservoir stimulation using guar-based fracturing fluid: A review. J. Nat. Gas Sci. Eng. 2019, 66, 107-125. [CrossRef]

25. Zhang, L.-F.; Zhou, F.-J.; Zhang, S.-C.; Li, Z.; Wang, J.; Wang, Y.-C. Evaluation of permeability damage caused by drilling and fracturing fluids in tight low permeability sandstone reservoirs. J. Petrol. Sci. Eng. 2019, 175, 1122-1135.

26. Liang, X.-Y.; Zhou, F.-J.; Liang, T.-B.; Wang, C.; Yuan, S. Impacts of low harm fracturing fluid on fossil hydrogen energy production in tight reservoirs. Int. J. Hydrog. Energy 2020, 45, 21195-21204. [CrossRef]

27. Wang, J.; Huang, Y.-X.; Zhang, Y.; Zhou, F.-J.; Yao, E.-D.; Wang, R. Study of fracturing fluid on gel breaking performance and damage to fracture conductivity. J. Petrol. Sci. Eng. 2020, 193, 107443. [CrossRef]

28. Almubarak, T.; Ng, J.-H.; Ramanathan, R.; Nasr-EI-Din, H.-A. Chelating agents for oilfield stimulation: Lessons learned and future outlook. J. Petrol. Sci. Eng. 2021, 205, 108832. [CrossRef] 